\title{
CICERO OOR GRONDHERVORMING
}

\author{
J P K Kritzinger (Universiteit van Pretoria)
}

\section{Inleiding}

In sy De Officiis 2.78-85 spreek Marcus Tullius Cicero die kwessie van grondhervorming op ' $n$ heel duidelike en eenvoudige manier aan. Hy gee ook 'n aantal voorbeelde, positief en negatief, van hoe die kwessie hanteer is en hanteer behoort te word. In hierdie artikel word die breër konteks van Boek 2 van die De Officiis eers kortliks geskets en daarna val die fokus op die grondkwessie. Dit is vir ons vandag 'n uiters relevante probleem, veral in die lig van die situasie in Zimbabwe en in die lig van vrese wat by wit Suid-Afrikaanse boere leef, met betrekking tot grootskaalse grondonteiening. Daar sal ook aandag gegee word aan spesifieke beginsels of riglyne wat Cicero belangrik ag en ten slotte sal die proses in Zimbabwe daaraan gemeet word.

\section{De Officiis Boek 2 - die breër konteks}

Voordat ons aandag gee aan die spesifieke gedeelte waarin Cicero hierdie kwessie aanspreek, is dit nodig om te kyk na die konteks waarbinne dit voorkom. Boek 2 van die De Officiis handel oor wat nuttig is en meer spesifiek oor wat nuttig is vir politieke opgang. Die grootste deel van die boek handel oor maniere waarop steun van medeburgers gewerf kan word (parr. 21-85). In paragrawe 52-85 bespreek Cicero die verkryging van steun deur die gee van finansiële uitgifte (parr. 52-64) of deur die lewering van persoonlike diens (parr. 65-85). Hy stel dit as volg in par. 52:

Sed expositis adulescentium officiis, quae valeant ad gloriam adipiscendam, deinceps de beneficentia ac de liberalitate dicendum est, cuius est ratio duplex; nam aut opera benigne fit indigentibus aut pecunia. Facilior est haec posterior locupleti praesertim, sed illa lautior ac splendidior et viro forti claroque dignior. Quamquam enim in utroque inest gratificandi liberalis voluntas, tamen altera ex arca, altera ex virtute depromitur, . . .

Nadat daar 'n uiteensetting gegee is van die pligte van jongmense, wat hulle in staat kan stel om roem te verwerf, moet daar vervolgens iets oor die doen van weldade en oor vrygewigheid gesê word. Daar is twee maniere om jou vrygewigheid te bewys: jy kan mense in nood help of deur persoonlike dienslewering óf met jou geld. Laasgenoemde opsie is makliker, veral vir welgesteldes, maar daardie eerste opsie bevorder groter aansien en verleen meer luister, en pas beter by die waardigheid van die invloedryke en beroemde man. En alhoewel daar in beide gevalle ' $n$ ruimhartige bereidwilligheid is om goed te doen aan ander, kom dit in die een geval uit die beursie, in die ander geval spruit dit egter voort uit deugsaamheid.

Onder persoonlike dienslewering word die volgende genoem: eerstens regsbystand, in welke geval regskundigheid en welsprekendheid beide handig te pas kom en tweedens diens aan die breër gemeenskap, spesifiek deur die beskerming van eiendomsregte en die vermyding van die instel van eiendomsbelasting. 
3. Die enger konteks: die voorbeelde van Lucius Aemilius Paulus, Scipio Aemilianus en Lucius Mummius

Dit is binne hierdie konteks dat Cicero in paragraaf 76 drie Romeine as rolmodelle voorhou en hulle aanprys vir hul optrede wat spreek van hul abstinentia (selfbeheersing). ${ }^{1}$ Die optrede van Lucius Aemilius Paulus, Scipio Aemilianus en Lucius Mummius spreek volgens Cicero van hulle onkreukbaarheid en integriteit.

Van L. Aemilius Paulus sê hy dat hy soveel geld vir die skatkis ingebring het dat dit 'n einde aan alle eiendomsbelastings meegebring het. Die belangrike opmerking wat hy daarna maak, is dat hierdie Paulus niks in sy huis ingedra het nie behalwe die ewigdurende gedagtenis van sy goeie naam. Hy het dus deur sy optrede roem verwerf vir sy familie en nageslag. Al het hy die geleentheid daartoe gehad, het hy nie homself verryk nie.

Hierdie man se seun, Scipio Aemilianus, ook bekend as Scipio Africanus, die Romeinse generaal van die Derde Puniese oorlog, het nadat hy in $146 \mathrm{vC}$ die baie ryk stad, Karthago vernietig het, die voorbeeld van sy pa, Aemilius Paulus gevolg en homself nie daardeur verryk nie. Cicero sê dat Africanus geensins meer welaf was nadat Karthago verslaan is nie.

In die derde plek noem hy die voorbeeld van Lucius Mummius, konsul in $146 \mathrm{vC}$ en mede-censor saam met Scipio Aemilianus in $142 \mathrm{vC}$. Hy het in $146 \mathrm{vC}$ die baie ryk stad Korinte verwoes en, net soos die ander twee, het hy nie die geleentheid om homself te verryk, uitgebuit nie. Cicero sê dat hy verkies het om Italië, eerder as sy eie huis, te versier. Hy voeg egter by dat Mummius se huis vir hom baie mooier gelyk het, nadat hy Italië mooigemaak het. Net soos in Aemilius Paulus se geval, het hy deur sy optrede vir sy huis, dit wil sê, vir sy familie en nageslag, naam gemaak en roem verwerf.

In paragraaf 77 sê Cicero dat daar geen skandeliker ondeug as hebsug is nie en veroordeel veral die voorkoms daarvan by leiers en regeerders. ${ }^{2}$ Hy sê verder dat dit nie net skandelik is om die staat uit te buit vir persoonlike gewin nie, maar selfs misdadig en goddeloos. Cicero sluit die paragraaf af deur te sê dat leiers van die staat op geen makliker manier die goedgesindheid van die menigte kan wen, as deur abstinentia en continentia nie:

Nulla autem re conciliare facilius benivolentiam multitudinis possunt ii, qui rei publicae praesunt, quam abstinentia et continentia

Hulle wat aan die hoof van die staat staan, kan op geen makliker manier die goedgesindheid van die volksmassa wen as deur hul selfbeheersing en onbaatsugtigheid nie.

Hierdie paragraaf staan dus in direkte kontras met die vorige paragraaf, met sy kritiek op hebsug (avaritia) as direkte teenhanger van daardie selfbeheersing (abstinentia) wat hy in paragraaf 76 aanprys.

1. Die woord abstinentia dui hier op die selfbeheersing van 'n invloedryke persoon, wat nie swig voor die versoeking van gierigheid nie. Cf. Lewis \& Short, (1980:12) s.v. abstinentia: "abstinence, self-restraint (the quality by means of which one abstains from unlawful desires, acts, etc., freedom from covetousness ..." Walsh (2000:81) vertaal abstinentia hier met "incorruptibility".

2. Nullum igitur vitium taetrius est, ut eo, unde digressa est, referat se oratio, quam avaritia, praesertim in principibus et rem publicam gubernantibus. (Om die bespreking terug te bring na die punt, vanwaar dit afgedwaal het: daar is dus geen skandeliker ondeug as hebsug nie, veral by leiers en by diegene wat die staat bestuur). 


\section{Grondhervorming en die kwytskelding van skuld}

Vervolgens betreur Cicero in paragraaf 78 eietydse grondhervorming asook die kwytskelding van skuld as maniere waarop gulsige leiers poog om die guns van die volk te wen. Cicero sê dat daar mense is wat die guns van die volk wil wen deur óf grondeienaars van hul grond te verdryf óf deur mense wat geld skuld, hul skuld vry te skeld. Hy veroordeel egter onmiddelik hierdie optrede en sê dat dit die "fondamente van die staat ondermyn" (labefactant fundamenta rei publicae). Hy kwalifiseer vervolgens die fondamente van die staat as eerstens concordia (eensgesindheid) en tweedens aequitas (billikheid). Cicero sê dat concordia nie moontlik is, wanneer sommiges van hulle besittings ontneem word, terwyl andere weer van hul skuld vrygeskeld word nie. Die ideaal van eensgesindheid bly in die slag omdat daar ' $n$ vyandigheid ontstaan tussen die nuwe eienaars van die grond en diegene van wie dit weggeneem is. Hy sê letterlik dat die een van wie die grond weggeneem is, 'n vyand is: Nam cui res erepta est, est inimicus (par. 79). Cicero sê ook die feit dat daar meer mense is wat ontvang het, as mense van wie daar onregverdiglik weggeneem is, maak dit nie méér geldig nie. Die rede wat hy vir hierdie stelling aanbied, is dat hierdie dinge nie volgens getal geoordeel word nie, maar volgens gewig: Non enim numero haec iudicantur, sed pondere (par. 79). Verder word die beginsel van aequitas totaal omvergewerp, as elkeen nie gegun word om te hou wat aan hom behoort nie. Cicero stel die vraag na die billikheid weer aan die einde van paragraaf 79 aan die orde in die vorm van 'n retoriese vraag:

Quam autem habet aequitatem, ut agrum multis annis aut etiam saeculis ante possessum qui nullum habuit habeat, qui autem habuit amittat?

Want watse billikheid is daar as ' $n$ man wat niks besit het nie, land kry wat vir baie jare of selfs geslagte in iemand anders se besit was en hy wat dit besit het, dit verloor?

Die billikheidsbeginsel word hier beskryf met die woorde suum cuique (letterlik: "sy eie vir elkeen", of: "vir elkeen wat hom toekom") en dit vorm van baie vroeg af 'n basiese beskrywing van geregtigheid (iustitia) ${ }^{3}$. Dit word normaalweg met die uitdrukking suum cuique tribuere ("om aan elkeen te gun wat hom toekom") beskryf. Cicero sê verder dat dít juis die kenmerkende eienskap van 'n staat en 'n stad is, dat daar vir elkeen vrye en onbelemmerde beheer oor hulle besittings moet wees: Id enim est proprium, ut supra dixi, civitatis atque urbis, ut sit libera et non sollicita suae rei cuiusque custodia.

\section{Die voorbeeld van Lysander}

In paragraaf 80 word na die grondhervorming verwys as hoc iniuriae genus (hierdie soort onreg) en vervolgens word die gevolge daarvan aan die hand van 'n voorbeeld geskets. Grondhervorming het daartoe gelei dat die Spartane vir Lysander uitgedryf en Agis, die koning, doodgemaak het. Dit is iets wat nog nooit vantevore in Sparta gebeur het nie en sedert daardie tyd het daar soveel tweespalt (discordia) geheers, dat daar tiranne aan bewind gekom het en dat vooraanstaandes verban is en die staat in duie gestort het. Dit het egter nie daar geëindig nie, maar ook die res van Griekeland getref soos 'n aansteeklike siekte wat by Sparta begin het en toe verder versprei het. Uit hierdie voorbeeld is dit duidelik dat die twee beginsels van aequitas en concordia in die slag gebly het en dit het tot die ineenstorting van

3. Vergelyk Van Zyl (1991: passim) vir 'n volledige bespreking van die noue verband tussen iustitia en aequitas. 
die staat gelei; 'n staat wat 'n baie goeie konstitusie gehad het. Net soos die woord iniuria die teenoorgestelde van iustitia en aequitas is, is discordia die teenoorgestelde van concordia.

\section{Die voorbeeld van Aratus van Sicyon}

Paragraaf 81 word ingelei met die woorde at vero (maar aan die ander kant) wat dui op 'n teenstelling met die voorafgaande, en hier word 'n positiewe voorbeeld verskaf in die verhaal van die Griek, Aratus van Sicyon, se hantering van die grondhervormingskwessie. Daar word gesê dat hy met reg aangeprys is. Die verhaal van Aratus word soos volg voorgehou: Nadat Sicyon vir 50 jaar onder die beheer van tiranne gestaan het, het Aratus die stad binnegekom en die tiran Nicocles in 'n onverwagse aanval verslaan en weer hulle verlore vryheid aan die burgers van Sicyon teruggegee. Hy het ook 600 bannelinge, wat destyds van die rykste inwoners was, laat terugkeer. Hy het egter spoedig kennis geneem van 'n groot probleem (magnam ... difficultatem) rondom die eiendomsreg van die verskillende groepe. Hy het gemeen dat dit baie onregverdig (iniquissimum) is dat diegene wat hy teruggebring het, hulle besittings, wat in ander mense se hande geval het, moes ontbeer. Aan die ander kant het hy dit ook nie eintlik as billik (non nimis aequum) beskou om besittings wat reeds vir 50 jaar in hul besit was, weg te neem nie. Baie van hierdie eiendomme het immers op regmatige wyse (sine iniuria), by wyse van erflatings, kooptransaksies en bruidskatte in hulle besit gekom en gevolglik kon hulle beskou word as die regmatige eienaars daarvan. Hy het toe geoordeel dat die eiendom nie van daardie mense weggeneem moet word nie en dat daar eerder kompensasie betaal behoort te word aan die voormalige eienaars.

In paragraaf 82 beskryf Cicero dat Aratus toe aangekondig het dat hy na Alexandrië gaan en dat die saak net daar gelos moet word totdat hy terugkeer. In Alexandrië het hy aan die ryk koning Ptolemaeus sy situasie verduidelik en maklik die koning oorreed om vir hom 'n groot bedrag geld te gee. Met sy terugkoms het Aratus 15 leiers gekry om hom te help om die sake te ondersoek van diegene wat ander se grond beset het sowel as van diegene wat hulle grond verloor het. Nadat daar 'n waardasie van die eiendom gemaak is, het Aratus daarin geslaag om sommiges te oorreed om eerder geld te aanvaar en van hulle eiendom afstand te doen. Ander het hy oorreed dat dit voordeliger is dat 'n bedrag gelykstaande aan die waarde van die eiendom uitbetaal word, as om hul eie grond terug te kry. Dit is volgens Cicero so goed hanteer, dat almal sonder klagte uiteengegaan het, nadat die eensgesindheid herstel is (concordia constituta).

In paragraaf 83 besing Cicero Aratus se lof verder en sê dat hy 'n groot man was. Cicero se Romeinse meerderwaardigheid slaan hier deur wanneer hy sê dat Aratus vanweë sy buitengewone verdienstelikheid netsowel 'n Romein kon gewees het. Ironies genoeg vergelyk Cicero dan op subtiele manier sy optrede met dié van twee Romeine, wanneer hy sê dat Aratus daartoe opgewasse was om met burgers te handel, anders as in twee gevalle by die Romeine, waar hulle die spies in die forum geplant het en die besittings van burgers deur 'n afslaer laat opveil het. Hy verwys hier na die konfiskerings onder Sulla (c. 82 vC) en Julius Caesar (c.46 vC). In teenstelling met hierdie Romeine, het daardie Griek gereken dat almal geraadpleeg moet word en op grond daarvan noem Cicero vir Aratus 'n wyse en buitengewone man. Cicero voeg dan by dat dit getuig van die hoogste redelikheid en wysheid van 'n goeie burger, om nie die belange van die burgers uitmekaar te skeur nie en om almal met dieselfde billikheid bymekaar te hou: 
At ille Graecus, id quod fuit sapientis et praestantis viri, omnibus consulendum putavit, eaque est summa ratio et sapientia boni civis, commoda civium non divellere atque omnis aequitate eadem continere.

Hierdie paragraaf word afgesluit op dieselfde trant waarop paragraaf 79 afgesluit is. Cicero bevraagteken weereens die billikheid van die toedrag van sake, naamlik dat iemand anders op die grond kan woon teen die wil van die grondeienaar, wat die grond gekoop het, daarop gebou het, dit in stand gehou het en vir alles betaal het. Hy sê dit is niks anders as om sommiges te beroof en aan ander te gee wat nie hulle eiendom is nie. Hierdie slotsom Quid est aliud aliis sua eripere, aliis dare aliena word net soos die vraag aan die einde van paragraaf 79 in die vorm van 'n retoriese vraag gestel. Dit weerspieël die verontwaardiging van die skrywer.

Nadat paragraaf 83 afgesluit is met hierdie retoriese vraag, word paragraaf 84 met 'n verdere vraag ingelei, maar hier gaan dit weer om die afskryf van skuld. Cicero bevraagteken die sin daarvan en impliseer eintlik dat dit nie sin maak dat iemand met jou geld jou grond koop en dat hy dit besit, terwyl jyself nie geld het nie. Hy waarsku ook dat skuld nooit die staat moet benadeel nie en sê dat daar baie maniere is waarop daar voorsorg getref kan word dat die rykes nie hul eiendom verloor nie en dat skuldenaars nie iemand anders se goed kry nie. Hierna maak Cicero 'n belangrike opmerking, naamlik dat daar niks is, wat die staat stewiger bymekaar hou as vertroue nie en dat daar nie sprake van vertroue kan wees as die betaling van skulde nie afgedwing word nie: Nec enim ulla res vehementius rem publicam continet quam fides, quae esse nulla potest, nisi erit necessaria solutio rerum creditarum.

Hier is dus weer sprake van dit wat 'n staat bymekaar hou (rem publicam continet), d.w.s. van eensgesindheid onder die bevolking. Fides (vertroue) word genoem as die belangrikste middel om dié eenheid te bewerkstellig. Hierdie vertroue word egter ondermyn indien skuld sommer so afgeskryf word. Dit is dalk belangrik om op die verskillende betekenismoontlikhede van die woord fides te let: dit kan gewoon "vertroue", "geloof" of "geloofwaardigheid" beteken, maar in die besigheidwêreld kan fides ook "krediet" of "kredietwaardigheid" beteken. ${ }^{4}$ Indien 'n regering hom skuldig maak aan korrupsie of onbillike hantering van sy onderdane, word die vertroue op alle terreine geskend en dit lei tot onenigheid. Cicero gebruik ook die geleentheid om hom daarop te beroem dat hy tydens sy konsulskap baie sterk gestaan het teen die praktyk van die afskrywing van skuld en dit trouens heeltemal uitgeroei het.

Paragraaf 85 vorm die afsluiting van hierdie onderafdeling en bevat dan ook samevattende opmerkings. Soos wat hy in paragraaf 80 na die konfiskering van grond as hoc iniuriae genus (hierdie soort onreg) verwys het, word hier op soortgelyke wyse na die kwytskelding van skuld en die konfiskering van grond verwys met die woorde hoc . . genere largitionis (hierdie soort spandabelrigheid). Hy sê egter dat diegene wat die staat sal beskerm, d.w.s. die toekomstige leiers, hulle sal distansieer van hierdie tipe verkwisting, waar daar aan sommiges gegee word en van ander weggeneem word. Verder sal hulle veral sorg dat elkeen sy eie eiendom behou ooreenkomstig die billikheid van die reg en die howe en sal hulle toesien dat die armer mense nie op grond van hulle lae status te na gekom word nie; ook dat jaloesie teenoor die rykes hulle nie sal verhinder om hulle eie goed te behou of terug te kry nie. Daarbenewens moet hulle met al die middele tot hul beskikking werk vir die uitbreiding van die Ryk, sy grondgebied en belastings. Die beginsel van billikheid (aequitas) word hier dus

4. Vergelyk Lewis \& Short (1980:746) s.v. fides: “. . . trust in a person or a thing, faith, confidence, reliance, credence, belief . . ." en "In partic., in mercant. language, credit". 
weer genoem en die woorde suum quisque teneat herinner sterk aan die woorde habere suum cuique van paragraaf 78. Die woord aequitate word egter gekwalifiseer deur iuris et iudiciorum en daarmee word daar spesifiek na die billikheid van die reg en die howe verwys. Dit is laastens ook belangrik dat die belange van die staat vooropgestel word.

\section{Aratus versus Mugabe}

Vervolgens word daar by wyse van 'n samevatting gekyk na wat wat Cicero sê oor die grondhervormingskwessie en daar word ook gewys op 'n aantal ooreenkomste en verskille met die situasie in Zimbabwe.

Cicero wys daarop dat sekere leiers grond onteien en aan hul volgelinge gegee het in 'n poging om die guns van die volkmassa te wen. President Robert Mugabe se grondhervormingsproses kan sekerlik ook beskou word as 'n poging om steun te werf. ${ }^{5}$ Dit is opvallend dat die program groot momentum begin kry het in die aanloop tot die algemene verkiesing in 2002. Volgens Johah Gokova, 'n lid van die Zimbabwiese National Constitutional Assembly, is die besetting van boerderygrond deur sogenaamde oorlogsveterane 'n ou Zanu-PF-verkiesingstruuk en word daar voor elke verkiesing 'n paar plase beset en die grond word aan die mense belowe. Ná die verkiesing word die plase egter aan senior party-amptenare gegee. ${ }^{6}$ Die grond wat onteien word, word veral aan oorlogsveterane en troue volgelinge van die regerende party beskikbaar gestel. ${ }^{7}$

Cicero pleit veral vir die handhawing van twee beginsels, naamlik billikheid (aequitas) en eensgesindheid (concordia), wat hy beskryf as die fondamente van die staat. Uit die manier waarop die grondhervorming in Zimbabwe bestuur is, is dit egter duidelik dat hierdie twee beginsels in die slag gebly het. Grondeienaars wat al vir jare en geslagte op hul grond geboer het, is met geweld van hul plase verjaag ${ }^{8}$ en die plaasarbeiders is eweneens swaar getref. ${ }^{9}$ In plaas van eensgesindheid heers daar nou tweespalt en van vrye en onbelemmerde beheer oor hul besittings is daar geensins sprake nie.

Hierbo het ons gesien dat Cicero in paragraaf 80 van sy De Officiis verwys na die negatiewe gevolge van Lysander van Sparta se grondhervorming, wat veroorsaak het dat die staat in duie gestort het en dat dit daarna die res van Griekeland soos 'n aansteeklike siekte getref het. In Zimbabwe het die ekonomie in duie gestort en daar is duisende mense wat

5. Vergelyk in dié verband die volgende aanhaling uit Beeld van 24/03/2000, p.15: "Grond, grond en nogmaals grond. Dit is dié towerwoord waarmee Mugabe en sy party al hoe meer probeer om kiesers aan hul kant te kry. Zanu-PF se manifes belowe dat prioriteitsgroepe grond sal kry: kleinboere, veterane van die vryheidsoorlog, voormalige politieke gevangenes, asook 'inheemse' sakelui wat wil boer'.

6. Beeld, 08/04/2000, p.2.

7. In Rapport van 28/04/2002, p.15 word berig van die twee Zimbabwiese vise-presidente wat ook voordeel getrek het uit die herverdeling van grond. In die een geval is die boer deur ' $n$ afvaardiging van amptenare gelas om die plaas binne 'n week te verlaat en daar is aan hom gesê dat al die werktuie en besproeiingstoerusting ook op die plaas agtergelaat moet word.

8. In Beeld van 17/04/2000, p.1 word byvoorbeeld berig oor die gewelddadige plaasbesetting waartydens mnr. David Stevens ontvoer en doodgeskiet is en vyf ander boere wat hom probeer help het, ontvoer en erg aangerand is. Hy was egter slegs die eerste een wat tydens die grondbesettings vermoor is.

9. So word daar byvoorbeeld in Beeld van 25/04/2000, p.1 soos volg berig: "Tientalle werkers op die Deanplaas in die Wedza-distrik suid van Harare is gister vrygelaat nadat hulle aangehou is deur 'n groep van meer as honderd. Verskeie van die werkers is wreed aangerand en het met brandwonde en gebreekte arms van hul ontvoerders ontsnap." 
honger ly as gevolg van die gebrek aan politieke en ekonomiese stabiliteit. ${ }^{10}$ Die negatiewe gevolge is verder geensins beperk tot die land self nie; dit beïnvloed die hele streek. In Namibië het president Sam Nujoma ook al gedreig om boere se grond te vat en dit is ook as 'n poging gesien om steun vir homself te werf. ${ }^{11}$ President Mugabe het ook self die grondloses in Namibië en in ander buurstate aangemoedig om die voorbeeld van die oorlogsveterane in sy land te volg en plase te beset indien boere nie hul grond wil afstaan nie. ${ }^{12}$ Verder is daar talle Zimbabwiërs wat die land verlaat en in buurlande met reeds hoë werkloosheidsyfers 'n ander heenkome moet vind. ${ }^{13}$

Eweneens het ons gesien hoe, in die voorbeeld van Aratus van Sicyon, Cicero aandui hoe so 'n grondkwessie na regte hanteer behoort te word. In die eerste plek het Aratus besef dat daar 'n groot probleem is en toe het hy met simpatieke oë na beide partye gekyk en besef dat beide partye billik behandel moet word. Daar word op die praktiese oplossing om kompensasie te betaal aan die voormalige eienaars besluit, maar aangesien daar nie geld daarvoor beskikbaar is nie, wend Aratus hom na Ptolemaeus II Philadelphus in Alexandrië en kry by hom geld. Vervolgens stel Aratus 'n 15-man kommissie aan om hom te help met die ondersoek en daar word waardasies van die eiendomme gemaak. Die laaste belangrike stap is die onderhandelings of "onderhandelde skikkings" met die betrokkenes: sommige bewoners ruil die grond in vir geld, in ander gevalle neem grondeisers geld as kompensasie. Aratus slaag dus daarin om die vrede te bewaar en die eensgesindheid te herstel. Indien President Mugabe se aanslag met dié van Aratus vergelyk word, skiet hy duidelik vér te kort en slaag hy definitief nie daarin om die proses op 'n billike en vreedsame manier te besleg nie. President Mugabe het dit self duidelik gestel dat hy nie in onderhandelings met boere belangstel nie. ${ }^{14}$ Indien sy verhouding met ander wêreldleiers beter was, sou hy ook sonder moeite kompensasiegeld kon kry, wat hom in staat sou stel om 'n soortgelyke onderhandelingsproses aan die gang te sit. Brittanje het ook inderdaad geld bewillig vir die doel, maar het sekere voorwaardes gestel, waaraan Zimbabwe nie voldoen het nie en gevolglik het die ooreenkoms in die slag gebly. ${ }^{15}$ Terwyl Aratus hier as 'n wyse en redelike man beskryf word, wat die belange van al die burgers op die hart dra, vertoon President

10. Tony Leon, die leier van die DA, skets die situasie in Zimbabwe soos volg in Rapport, 2002/07/07, p.14: "In twee kort jare het dié voormalige broodmandjie van Afrika ons plaaslike ground zero geword. Dis 'n skrikwekkende plek met massaverhongering, totale ekonomiese ineenstorting, plundering en vernietiging weens 'n skrikbewind van die staat".

11. Vergelyk Beeld, 30/08/2002, p.12: “Terselfdertyd is sy (i.e. President Nujoma se) dreigemente teen wit grondeienaars 'n manier om goedkoop politieke gewildheid te probeer koop ..."

12. Beeld, 27/05/2000, p.1.

13. In Beeld van 20/04/2000, p.2 word President Mbeki soos volg aangehaal in dié verband: "As Zimbabwe onstabiel is, sal mense oor die grens stroom. Ons het al reeds baie Zimbabwiërs wat uit die land gedryf word op soek na beter geleenthede en werk in Suid-Afrika. Onstabiliteit en meer skokke in Zimbabwe sal net verder oorspoel."

14. In Beeld, 29/08/2002, p.1, word soos volg daaroor berig: "In Zimbabwe het pres. Robert Mugabe gister gesê daar is geen moontlikheid van enige onderhandelings tussen hom en wit boere oor grondhervorming nie. Dit kom op dieselfde dag as regter Benjamin Paradza se bevinding in die hooggeregshof in Harare dat die art. 8beslagleggingsbevele wat aan 54 boere bestel is, onwettig is".

15. Volgens Rapport, 23/09/2001, p.15, sou Brittanje kragtens die Abuja-akkoord van 6 September 2001, 'n bedrag van 36 miljoen pond (R 458 miljoen) vir grondhervorming in Zimbabwe beskikbaar stel, met díe voorwaarde dat daar binne die bepalings van die reg en die grondwet opgetree sou word in die herverdeling van landbougrond. Volgens die Commercial Farmers' Union is daar egter reeds binne die eerste twee weke ná die Abuja-ooreenkoms twintig plase binnegeval. 
Mugabe al hoe meer as 'n dwaas, wat duidelik verdeeldheid skep tussen die burgers van Zimbabwe en nie die landsbelang voorop stel nie.

8. Slot

Cicero bied in hierdie gedeelte van die De Officiis sy siening van die hantering van grondgeskille en gebruik beide positiewe en negatiewe voorbeelde (exempla) om dit te illustreer. Daar is in hierdie artikel veral gelet op die proses van geskilbeslegting wat hy voorstel, en die beginsels wat hy as belangrik beskou. Alhoewel hierdie skrywer baie deeglik bewus is daarvan dat die omstandighede totaal verskil, word daar van die standpunt uitgegaan dat die beginsels wat voorgehou word, steeds geld en dat ons huidige situasie in Suidelike Afrika ook daaraan gemeet kan word. Miskien sal die geskiedenisboeke vir President Mugabe op dieselfde manier as voorbeeld gebruik as wat Cicero vir Lysander gebruik het. Hopelik sal President Mbeki eerder positief met die voorbeeld van Aratus van Sicyon geassosieer word. ${ }^{16}$

\section{BIBLIOGRAFIE}

Lewis, C T and Short, C 1980. A Latin dictionary. Oxford: Clarendon Press.

Dyck, A R 1996. A commentary on Cicero, De Officiis. Ann Arbor: University of Michigan Press.

Walsh, P G (trans.) 2000. Cicero. On obligations. Oxford World's Classics. Oxford: Oxford University Press.

Van Zyl, D H 1991. Justice and Equity in Greek and Roman legal thought. Pretoria: Academica.

Winterbottom, M (ed.) 1994. De Officiis M. Tulli Ciceronis. New York: Oxford University Press.

16. In Rapport van 03/06/2001, p.18 word berig dat President Mbeki in 'n onderhoud met 'n Londense koerant gesê het dat grondbesettings soos dié in Zimbabwe nie in Suid-Afrika geduld sal word nie. In dieselfde berig word die belangrikheid van onderhandeling beklemtoon: "Onderhandeling met alle partye bly steeds die aangewese uitweg, soos juis die skikking by Lydenburg getoon het, waar die 'grondbeginsel' van 'gewillige koper, gewillige verkoper' uiteindelik gehandhaaf en 'n kompromis oor die prys van die omstrede grond aangegaan is". 